\title{
Epidemiology and phylogenetic analysis of hepatitis D virus infection in Australia
}

Kathy Jackson ${ }^{1}$, Jennifer MacLachlan ${ }^{1}$, Benjamin Cowie ${ }^{1}$, Stephen Locarnini ${ }^{1}$, Scott Bowden $^{1}$, Nasra Higgins ${ }^{2}$, Theo Karapanagiotidis ${ }^{1}$, Suellen Nicholson ${ }^{1}$ and Margaret Littlejohn $^{1}$

${ }^{1}$ Victorian Infectious Diseases Reference Laboratory, Doherty Institute

${ }^{2}$ Department of Health and Human Services Victoria

\section{Authors positions:}

1. Kathy Jackson - Senior Scientist, Research and Molecular Development Laboratory, Victorian Infectious Diseases Reference Laboratory, Doherty Institute

2. Jennifer MacLachlan - Senior epidemiologist, Epidemiology Unit, Victorian Infectious Diseases Reference Laboratory, Doherty Institute

3. Assoc Professor Benjamin Cowie - Director, Epidemiology Unit, Victorian Infectious

Diseases Reference Laboratory, Doherty Institute

4. Professor Stephen Locarnini - Head, Research \& Molecular Development, Victorian Infectious Diseases Reference Laboratory, Doherty Institute

5. Professor D.Scott Bowden - Head, Molecular Microbiology, Victorian Infectious Diseases Reference Laboratory, Doherty Institute

6. Dr Nasra Higgins, Epidemiologist, Communicable Disease Epidemiology and Surveillance, Department of Health and Human Services Victoria

7. Theo Karapanagiotidis - Senior Scientist, Serology Department, Victorian Infectious Diseases Reference Laboratory, Doherty Institute

8. Suellen Nicholson - Head, Serology Department, Victorian Infectious Diseases Reference Laboratory, Doherty Institute

9. Dr Margaret Littlejohn - Senior Scientist, Research and Molecular Development Laboratory, Victorian Infectious Diseases Reference Laboratory, Doherty Institute

\section{Author Contribution:}

Kathy Jackson: Conception, design and conduction of experiments, wrote manuscript Jennifer MacLachlan: Ethics submission, data analysis, author and review of manuscript Benjamin Cowie, Stephen Locarnini, Scott Bowden: review of manuscript Nasra Higgins, Theo Karapanagiotidis, Suellen Nicholson: Supply of data Margaret Littlejohn: Phylogenetic analysis, review and editing of manuscript

This is the author manuscript accepted for publication and has undergone full peer review but has not been through the copyediting, typesetting, pagination and proofreading process, which may lead to differences between this version and the Version of Record. Please cite this article as doi: 10.1111/imj.13967

This article is protected by copyright. All rights reserved. 
Corresponding Author*: Kathy Jackson

Phone: +6193429345

Email: kathy.jackson@mh.org.au

Fax: +6193429696

Address: VIDRL, Doherty Institute 792 Elizabeth Street, Melbourne, Australia 3000

Text Word Count: 3000

Abstract word count: 235

Disclosure Statement: The authors have no conflicts of interest to disclose.

\title{
Epidemiology and phylogenetic analysis of hepatitis D virus infection in Australia
}

\begin{abstract}
Words:235)
Background: The incidence and trends in hepatitis D virus (HDV) in Australia have not been recently assessed and the circulating genotypes have never been determined.

Aim: This study aimed to characterise the current virology and epidemiology of HDV.

Methods: Notifiable disease surveillance and laboratory testing data were analysed to assess demographics, risk factors, and trends. HDV serology and RNA testing were performed on requested samples from 2010-2016. Sequencing of a 500 nucleotides amplicon of the delta antigen and phylogenetic analysis of the strains from 2009-2016 was also conducted.

Results: Ninety HDV notifications were reported to the Victorian Department of Health and Human Services between 2010-2016. The majority (64.4\%) of those diagnosed were born overseas, most commonly in Sudan, Pakistan and Vietnam. Over the same period 190 patients tested positive for anti-HDV serology and 166 for HDV RNA. Sequencing of isolates from 169 individuals between 2009 and 2016 revealed 80.5\% strains were genotype 1, 16\% genotype 5 and $3.5 \%$ genotype 2 . Phylogenetic analysis confirmed relatedness of strains from birth country; revealed the presence of the "Pacific Island" genotype 1 strain in Queensland; and supported possible transmission in correctional facilities and within families.
\end{abstract}

Conclusions: This study demonstrates the ongoing need for routine HDV screening and engagement in clinical care for people living with HBV in Australia. epidemiologic findings highlight the diversity in those affected and provides insights into the local and global geographic distribution and transmission patterns. 


\section{Key words}

Hepatitis D virus

Epidemiology

Genotype

Phylogeny

This article is protected by copyright. All rights reserved. 


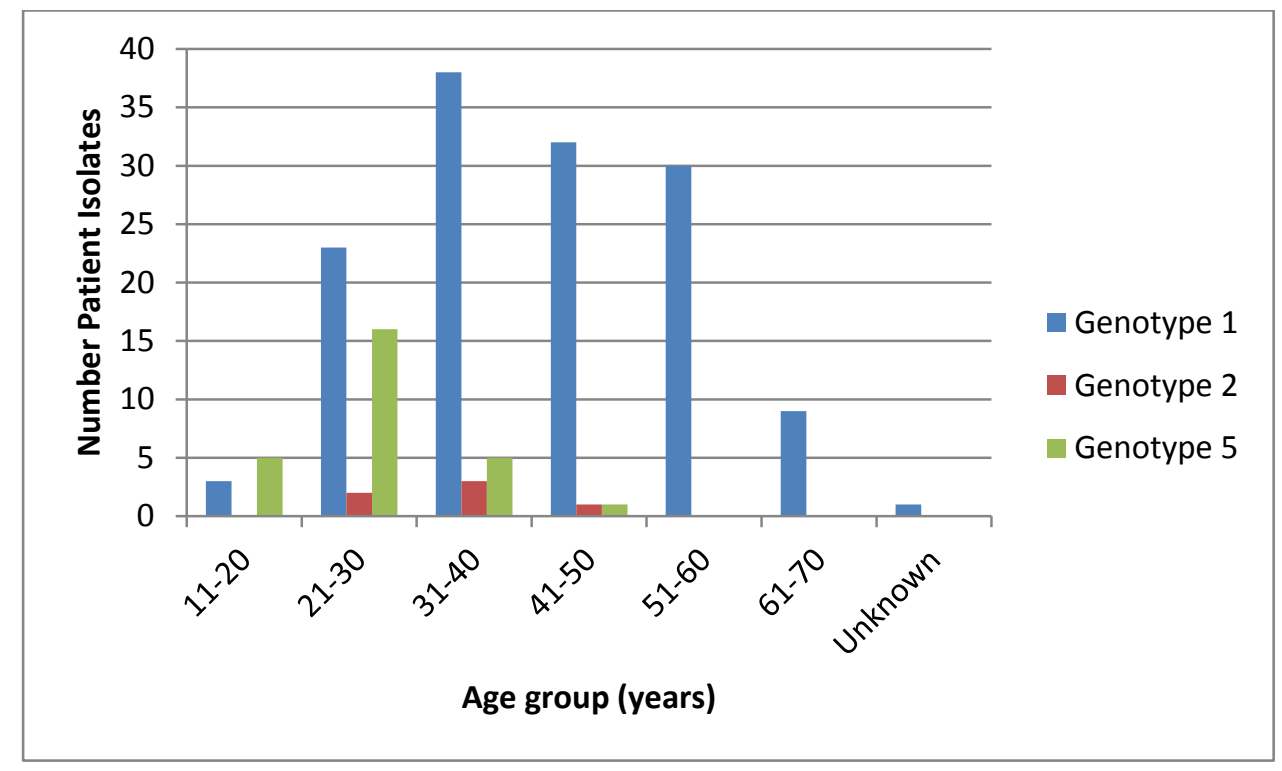

Figure 1a. The age of the patients at the time of HDV RNA detection

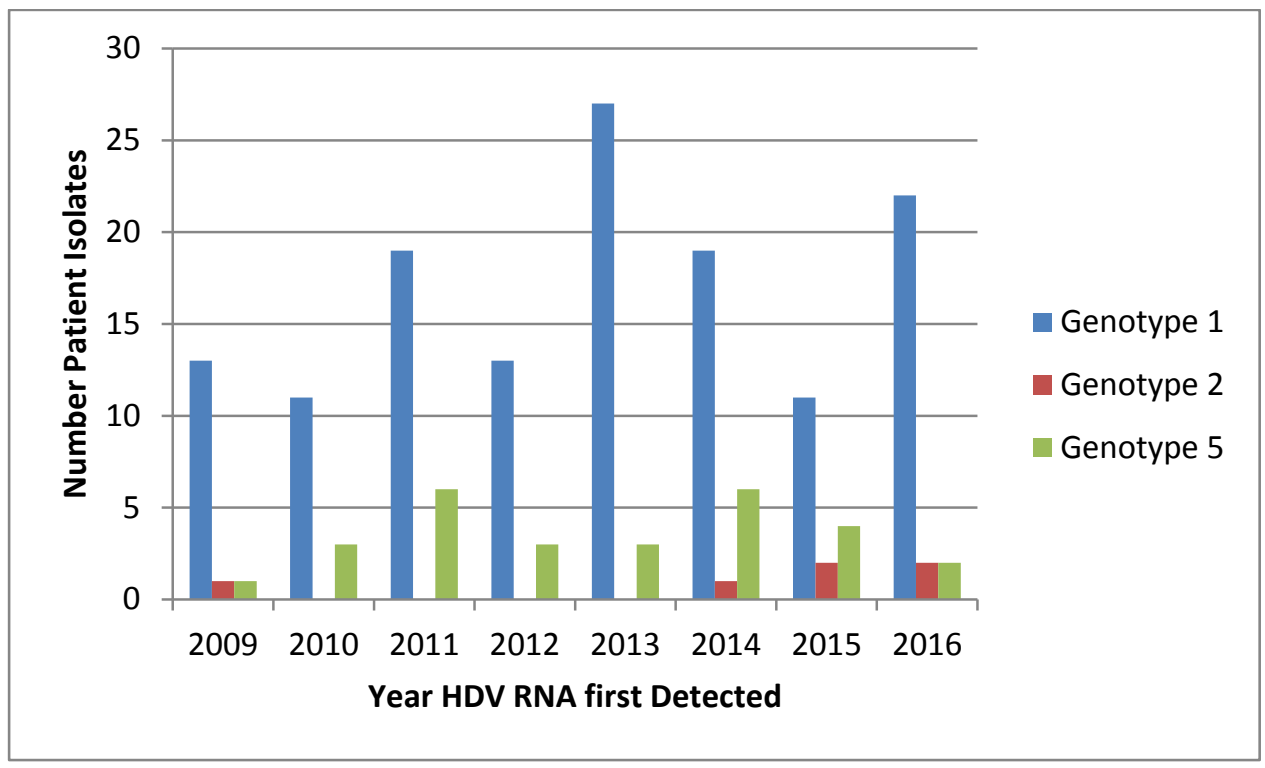

Figure1b. Shows the genotypes prevailing in the year HDV RNA was first detected

This article is protected by copyright. All rights reserved. 


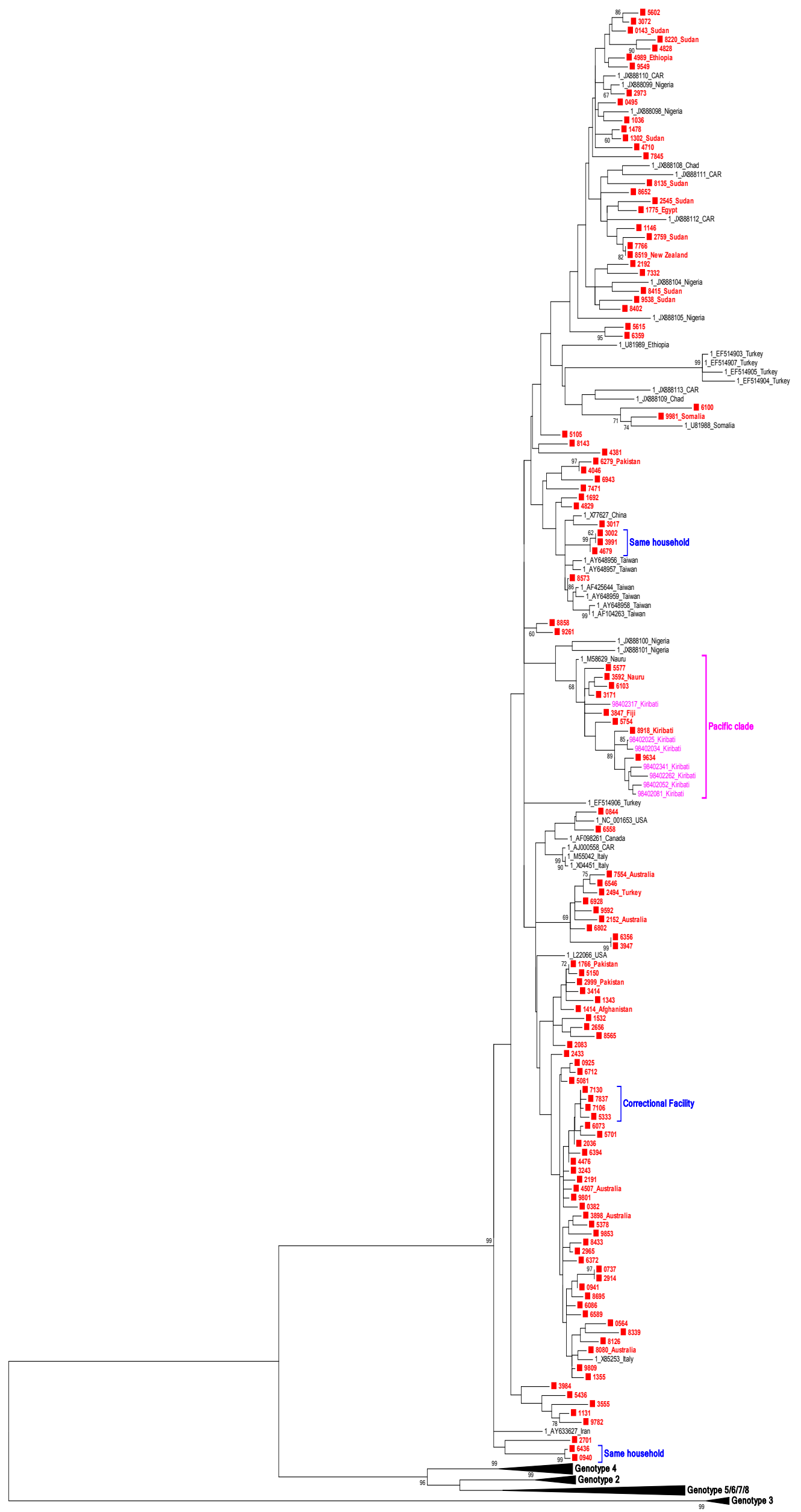

Figure 2. A

This article is protected by copyright. All rights reserved. 
Figure 2. A maximum likelihood phylogenetic tree showing the inferred relationship between the genotype 1 sequences isolated from this study and HDV sequences of known genotype retrieved from Genbank (403nt) Accession numbers and country of origin of the sequences downloaded from Genbank are indicated on the tree. Support values for the branches $>60 \%$ are indicated. The HDV sequences from this study are marked in red with known country of origin indicated. 


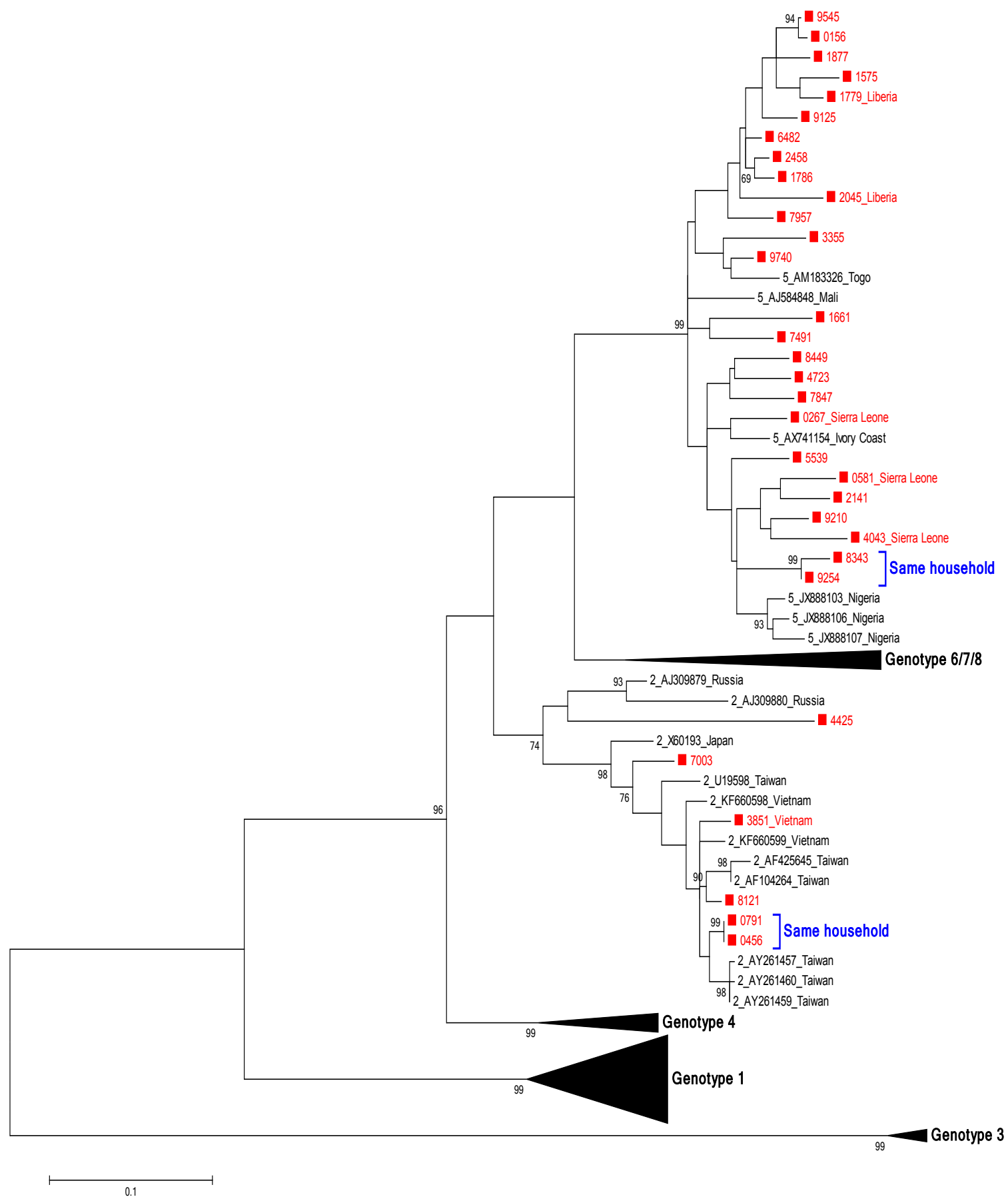

This article is protected by copyright. All rights reserved. 
Figure 3. A maximum likelihood phylogenetic tree showing the inferred relationship between the genotype 2 and 5 sequences isolated from this study and HDV sequences of known genotype retrieved from Genbank (401nt) Accession numbers and country of origin of the sequences downloaded from Genbank are indicated on the tree. Support values for the branches $>60 \%$ are indicated. The HDV sequences from this study are marked with a red square, with known country of origin indicated. 


\section{Epidemiology and phylogenetic analysis of hepatitis D virus infection in Australia}

Kathy Jackson ${ }^{1}$, Jennifer MacLachlan ${ }^{1}$, Benjamin Cowie ${ }^{1}$, Stephen Locarnini ${ }^{1}$, Scott Bowden $^{1}$, Nasra Higgins ${ }^{2}$, Theo Karapanagiotidis ${ }^{1}$, Suellen Nicholson ${ }^{1}$ and Margaret Littlejohn $^{1}$

${ }^{1}$ Victorian Infectious Diseases Reference Laboratory, Doherty Institute

${ }^{2}$ Department of Health and Human Services Victoria

\section{Authors positions:}

1. Kathy Jackson - Senior Scientist, Research and Molecular Development Laboratory, Victorian Infectious Diseases Reference Laboratory, Doherty Institute

2. Jennifer MacLachlan - Senior epidemiologist, Epidemiology Unit, Victorian Infectious

Diseases Reference Laboratory, Doherty Institute

3. Assoc Professor Benjamin Cowie - Director, Epidemiology Unit, Victorian Infectious

Diseases Reference Laboratory, Doherty Institute

4. Professor Stephen Locarnini - Head, Research \& Molecular Development, Victorian Infectious Diseases Reference Laboratory, Doherty Institute

5. Professor D.Scott Bowden - Head, Molecular Microbiology, Victorian Infectious Diseases Reference Laboratory, Doherty Institute

6. Dr Nasra Higgins, Epidemiologist, Communicable Disease Epidemiology and Surveillance, Department of Health and Human Services Victoria

7. Theo Karapanagiotidis - Senior Scientist, Serology Department, Victorian Infectious Diseases Reference Laboratory, Doherty Institute

8. Suellen Nicholson - Head, Serology Department, Victorian Infectious Diseases Reference Laboratory, Doherty Institute

9. Dr Margaret Littlejohn - Senior Scientist, Research and Molecular Development Laboratory, Victorian Infectious Diseases Reference Laboratory, Doherty Institute

\section{Author Contribution:}

Kathy Jackson: Conception, design and conduction of experiments, wrote manuscript Jennifer MacLachlan: Ethics submission, data analysis, author and review of manuscript Benjamin Cowie, Stephen Locarnini, Scott Bowden: review of manuscript Nasra Higgins, Theo Karapanagiotidis, Suellen Nicholson: Supply of data Margaret Littlejohn: Phylogenetic analysis, review and editing of manuscript

Corresponding Author*: Kathy Jackson

Phone: +6193429345

Email: kathy.jackson@mh.org.au

Fax: +6193429696

Address: VIDRL, Doherty Institute 792 Elizabeth Street, Melbourne, Australia 3000 
Text Word Count: 3000

Abstract word count: 235

Disclosure Statement: The authors have no conflicts of interest to disclose.

\begin{abstract}
Words:235)
Background: The incidence and trends in hepatitis D virus (HDV) in Australia have not been recently assessed and the circulating genotypes have never been determined.

Aim: This study aimed to characterise the current virology and epidemiology of HDV.

Methods: Notifiable disease surveillance and laboratory testing data were analysed to assess demographics, risk factors, and trends. HDV serology and RNA testing were performed on requested samples from 2010-2016. Sequencing of a 500 nucleotides amplicon of the delta antigen and phylogenetic analysis of the strains from 2009-2016 was also conducted.

Results: Ninety HDV notifications were reported to the Victorian Department of Health and Human Services between 2010-2016. The majority (64.4\%) of those diagnosed were born overseas, most commonly in Sudan, Pakistan and Vietnam. Over the same period 190 patients tested positive for anti-HDV serology and 166 for HDV RNA. Sequencing of isolates from 169 individuals between 2009 and 2016 revealed 80.5\% strains were genotype 1, 16\% genotype 5 and $3.5 \%$ genotype 2 . Phylogenetic analysis confirmed relatedness of strains from birth country; revealed the presence of the "Pacific Island" genotype 1 strain in Queensland; and supported possible transmission in correctional facilities and within families.
\end{abstract}

Conclusions: This study demonstrates the ongoing need for routine HDV screening and engagement in clinical care for people living with HBV in Australia. epidemiologic findings highlight the diversity in those affected and provides insights into the local and global geographic distribution and transmission patterns.

\title{
Key words
}

Hepatitis D virus

Epidemiology

Genotype

Phylogeny

\section{Epidemiology and phylogenetic analysis of hepatitis D virus infection in Australia}

\section{Introduction}


Hepatitis D virus (HDV) is estimated to infect 10-20 million people worldwide $(1,2)$. It is a small, satellite single stranded RNA virus that requires the surface antigen of hepatitis B virus (HBV) for assembly and transmission $(3,4)$, and is associated with faster progression to cirrhosis, hepatic decompensation, hepatocellular carcinoma and death than HBV monoinfection (5-7). Transmission of HDV in endemic areas is purportedly through horizontal intra-familial spread, although sexual transmission (6), injecting drug use (IDU) and unsafe medical and dental practices are also risk factors $(8,9)$. Prevalence is not evenly distributed, with higher burden of infection occurring in Mediterranean Europe, the Amazon Basin, SubSaharan Africa, and parts of Asia (10).

Eight HDV genotypes have been identified which differ by $19-40 \%$ over their genome sequence $(6,11-13)$. Genotype 1 is found worldwide $(13,14)$, while genotypes 2 and 4 are found in Taiwan and Japan and genotype 2 has also been identified in Russia and Vietnam (15-17). Genotype 3 has been identified in the Amazon Basin $(18,19)$, and genotypes 5-8 are of African origin (20). Although further research is required there is evidence that genotype affects natural history and severity of outcomes from HDV infection (6).

Determining HDV infection status is critical for all people living with chronic hepatitis B (CHB) as the interplay between the two viruses can complicate clinical management $(21,22)$. Previous estimates from Victoria, Australia indicate that around 5\% of people living with CHB are also infected with HDV, and that provision of HDV testing is suboptimal (9). Identifying the distribution and risk factors for infection can assist in guiding those at risk.

This study aims to provide a comprehensive assessment of the current epidemiology of HDV in Victoria, and molecular virology of HDV in Australia, including prevalence and demographic factors, as well as genotypic distribution and phylogenetic characteristics of prevalent HDV isolates.

\section{Materials and Methods}

Data regarding HDV were obtained from two sources: notifications from laboratories and diagnosing clinicians to the Victorian Department of Health and Human Services (DHHS); and records of HDV testing held by the Victorian Infectious Diseases Reference Laboratory (VIDRL).

Ethics approval for this study was granted by the Melbourne Health Human Research Ethics Committee. 


\section{Notifications data}

There is a legal requirement for laboratories to report new diagnoses of positive anti-HDV serology to the Australian health department. Notifications for HDV infection in 2010 to 2016 were obtained from DHHS Victoria, in a de-identified format. Median and interquartile range of age at diagnosis was calculated; and the distribution of cases according to sex, country of birth, indigenous status, reported history of IDU, and residence in a correctional facility assessed. HBV diagnosis date was recorded, and the median time lag between HBV and HDV notification determined according to country of birth, age, sex, and IDU history. Significance of differences in time lag was assessed using the Wilcoxon rank-sum test.

Summary notifications data for the period 2000-2009, obtained during a previous analysis (9), were included for assessment of trends over time. Significance of difference in proportions between the two time periods was assessed using the two-sample test of proportions and difference in medians using the Wilcoxon rank-sum test.

Identifiable surveillance data were also used for the purposes of matching to laboratory data to obtain country of birth information for genotype isolates. Data were matched according to pre-defined rules using name, date of birth, and residential address. After matching, all identifying variables were removed, and a separate extract of de-identified data was used for epidemiological analyses to protect confidentiality. In accordance with ethics requirements, no information other than country of birth was matched to laboratory data.

\section{Laboratory data}

VIDRL is a specialised laboratory that performs the majority of HDV serological testing in Victoria; and to our knowledge all PCR testing in Australia. This study included all sera sent to VIDRL for HDV antibody (anti-HDV) and HDV antigen (HDAg) testing, as well as PCR testing, between 2010 and 2016. PCR positive isolates received between 2009 and 2016 were sequenced and genotyped.

\section{Serological assays}


Anti-HDV and HDVAg were assayed using the DiaSorin S.p.A. Diagnostics anti-delta enzyme immunoassay (EIA) (ETI-AB-DELTAK-2) and DiaSorin S.p.A. Diagnostics EIA (ETI-DELTAK-2) (Saluggia (VC), Italy) respectively as per manufacturer's instructions.

\section{Sequencing and Phylogenetic Analysis}

Serum samples were stored at $-70^{\circ} \mathrm{C}$. RNA was extracted with the QIAamp Viral RNA Mini Kit (QIAGEN, Hilden, Germany) as per manufacturer's instructions. The RNA was heated at $100^{\circ} \mathrm{C}$ for 5 minutes to relax the secondary structure; quenched on ice and a screening PCR was performed as previously described (14). HDV RNA positive samples from 2009 to 2016 were then sequenced. Sequencing and genotyping was performed on a $500 \mathrm{bp}$ product directed to the 3' end of the gene encoding the large delta antigen and associated ribozyme using the primer set, detailed below.

Reverse transcription of RNA was performed using SuperScript ${ }^{\circledR}$ VILO ${ }^{\mathrm{TM}}$ cDNA Synthesis (Life Technologies, California, US), in accordance with the manufacturer's instructions with omission of the 10 minute room temperature incubation to delay/prevent reformation of secondary structure. The cDNA was amplified using primers: LCF (5'TGGCTCTCCCTTAGCCATCCGA) and R1as (5'-GAAGGAAGGCCCTCGAGAACAAG). The reaction mix contained 1U HotStar Taq Plus DNA polymerase (Qiagen, Hilden, Germany), $10 \mathrm{X}$ buffer, $0.16 \mathrm{mM}$ dNTP, $4 \mu 1$ template and $0.2 \mu \mathrm{M}$ each primer in a $25 \mu 1$ volume.

The PCR conditions were as follows: $94^{\circ} \mathrm{C}$ for 10 minutes; 50 cycles of: $94^{\circ} \mathrm{C}$ for 1 minute, $55^{\circ} \mathrm{C}$ for 30 seconds and $72^{\circ} \mathrm{C}$ for 1 minute; $72^{\circ} \mathrm{C}$ for 10 minutes. The amplicons were purified with ExoSAP-IT (Affymetrix, CA, USA), and sequenced with the BigDyeTerminator (AppliedBiosystems, CA, USA) as previously described (23). HDV sequences were aligned with 83 HDV sequences from GenBank (24) using the MAFFT program (25), followed by manual correction using BioEdit v7.0.5 (26). Phylogenetic analysis was performed using the Molecular Evolutionary Genetics Analysis v5 software (MEGA 5) (27). The HDV isolates were genotyped based on the maximum likelihood (ML) phylogenetic tree generated using the $\mathrm{GTR}+\mathrm{G}+\mathrm{I}$ substitution model, as proposed by the model testing program in MEGA5, with 1000 bootstrap replicates. Evolutionary divergence analysis was conducted using the Maximum Composite Likelihood model. 
The number of individuals with each genotype was assessed according to age group and state/territory, and significance of difference in proportions according to age group tested using the two-sample test of proportions.

\section{Results}

\section{Notifications Data}

Between 2010 and 2016, 90 cases of HDV were reported to DHHS, fluctuating from 7 to 23 per year. The majority of subjects were male $(59,65.6 \%)$ and median age at diagnosis was 40 years (IQR 31-50, Table 1). Fifty eight individuals were born overseas (64.4\%), with common countries including Sudan (19 cases, $21.1 \%$ of total), Pakistan and Vietnam (6 cases each, 6.7\%, Table 1). Eighteen individuals were born in Australia (18.9\%), while 15 (16.7\%) did not report birth country. None were reported as being Aboriginal and/or Torres Strait Islander.

IDU was a reported risk factor in 22 cases (24.4\%). Nearly half reported no history of IDU (44 cases, 48.9\%), while in 24 (26.7\%) IDU status was not recorded. Five individuals (5.6\%) were in a correctional facility at time of diagnosis. The most common reported reason for testing was history of hepatitis B infection (42 cases, 46.7\%), followed by clinical factors such as abnormal liver function tests (26 cases, $25.2 \%)$.

Of the 90 HDV cases, 66 (73\%) also had a HBV notification recorded. The median time lag between diagnosis of HBV and of HDV was 5.5 months, with the shortest being 4 days and the longest 16 years. Nearly one third of cases were diagnosed with HDV within a month of their HBV diagnosis. The median time lag appeared to vary according to country of birth. The time lag for those born in Sudan (24.8 months) was significantly longer than those born in all other overseas countries combined ( 3.8 months, $\mathrm{p}=0.036$ ). No variation in time lag was seen according to sex, age, or history of IDU (data not shown).

Compared to the previous period (2000-2009), significant increases were observed in median age (34 to 40 years, $p=0.006)$ and proportion of cases born overseas $(46.0 \%$ to $64.4 \%$, $\mathrm{p}=0.013)$, in particular Sudan ( $10.3 \%$ to $21.1 \%, \mathrm{p}=0.050)$ and Pakistan ( 0 to $6.7 \%, \mathrm{p}=0.014$, Table 1). Potential decreasing trends, which did not reach statistical significance, were seen in the proportion of cases that were male $(77.0 \%$ to $65.6 \%, \mathrm{p}=0.093)$, and those with a history of IDU (34.4\% to $24.4 \%, \mathrm{p}=0.14)$. 
The overall time lag between HBV and HDV notification shortened substantially from 20002009 and 2010-2016, from 2.3 years to 5.5 months $(\mathrm{p}=.0 .036)$, however there was a suggestion of increase in those born in Sudan but this did not reach statistical significance (3.8 months to 2.1 years, $\mathrm{p}=0.11$ ).

\section{Laboratory testing data}

5078 individual patient samples were tested for HDV serology during 2010-2016. 190 of the subjects had detectable anti-HDV (3.8\%). The majority, $120(72 \%)$ of these were male. Table 2 shows the breakdown of antibody requests and positivity by year. The number of serology requests increased during the period, nearly tripling between 2010 and 2016. Only five samples $(0.09 \%)$ tested positive for HDAg and all of these were also anti-HDV positive.

Between 2010 and 2016 there were 1,351 requests for HDV PCR from 890 patients, of which 394 samples (from 166 patients) tested positive (18.8\% patients). Of these, 131 (69\%) were male. Table 2 shows the breakdown of PCR requests and positivity by year. $39 \%$ of requests for PCR testing had a positive serology result previously recorded. The remaining $69 \%$ subjects may have had HDV serology performed interstate or elsewhere.

Table 3 shows that only $48 \%$ of anti-HDV samples had follow-up PCR requests. To prove the importance of following up on positive serology; in 2013 and 2014 PCR testing was performed on 20 random anti-HDV positive samples from individuals that did not have PCR requested. Half $(50 \%)$ of these had detectable HDV RNA. There were no individuals that had detectable HDV RNA and non-detectable antibodies to HDV.

\section{Genotyping/Phylogenetic Analysis}

Between 2009 and 2016, 181 patients tested positive for HDV RNA, and isolates from 169 were sequenced. The majority (136 isolates, 80.5\%) were genotype 1; 27 (16\%) genotype 5; and $6(3.5 \%)$ genotype 2, and genotype 1 was the majority in all years (Figure 1a). Age at diagnosis ranged from 17-69 years, however all non-genotype 1 isolates occurred in those under 50 (Figure 1a). The proportion aged under 50 was significantly higher in those with genotype 2 or $5(100 \%)$ than those with genotype $1(71.0 \%$; $<<0.001)$. The majority of those genotyped were residents of Victoria (35\%) or Queensland (34\%). The remaining isolates were from New South Wales (11\%), South Australia (17\%), Northern Territory (2\%), and Western Australia (1\%). 
Comparing phylogenetic analysis of the sequences to the country of birth identified from the surveillance data indicated that patients born in countries in Africa with genotype 1 strains cluster with previously identified African genotype 1 strains (Figure 2). Eight patients from Queensland had isolates that clustered with the previously reported Pacific Island (PI) clade (14). Further investigation revealed that three of these patients were born in Fiji, Kiribati and Nauru. The majority of genotype 1 strains clustered with those from Europe and the Middle East, while genotype 2 strains were isolated from individuals born in Vietnam (Figure 3). Genotype 5 strains originated from West to Central African countries such as Sierra Leone, Liberia and Nigeria (Figure 3). Across all genotypes, there were four clusters of sequences ( $>99 \%$ bootstrap value) where the individuals were identified as having the same residential address. In addition, we identified a cluster of five sequences where the individuals were currently residing in a correctional facility. Evolutionary divergence analysis of this cluster showed $99.1 \%$ similarity from averaging over all sequence pairs within the group. In comparison, the overall group of genotype 1 sequences with country of birth in Europe/Asia (this study) showed $95.78 \%$ similarity (data not shown).

\section{Discussion}

This is the first study to investigate the epidemiology, genotypes and phylogeny of HDV in Australia. The analysis demonstrates that migration is playing an increasingly important role in the distribution and genotypic characteristics of this unique virus although there is still evidence of transmission in Australia through IDU and other routes.

There was a continued shift in epidemiology of notifications data as previously observed (9), with increasing average age, a reduction in male predominance, and those diagnosed less likely to have a history of IDU (Table 1). The predominant countries of birth also changed, with Sudan and Pakistan being more common, reflecting changing migration patterns. This highlights the importance of recommending HDV screening for all those diagnosed with CHB (21), as many subjects diagnosed with HDV were born in regions considered to have low prevalence (6). The average time lag between HBV and HDV diagnosis during 20102016 was less than a quarter of that in 2000-2009, suggesting improvements in HDV screening after a new HBV diagnosis. Overall, the increase in HDV cases detected, the improved proportion tested opportunistically compared to symptomatically, and shortening of the lag between HBV and HDV diagnosis, suggest improvements in clinical care provision to those living with CHB. It is encouraging to note that the large increase in the number of HDV 
serology tests in Victoria suggests improved awareness of the need for screening. As the proportion of tests which are positive has remained relatively stable, this suggests an expansion in the uptake of testing within individuals who are at risk of HDV infection.

Although positive serology results should be followed by PCR testing to establish whether current HDV infection is present, less than half of positive results in this study had a clinician-initiated request for PCR testing (Table 2). Furthermore, of those who were tested even though a PCR was not specifically requested, half of the samples were positive (Table 3). Therefore, in 2015 VIDRL adopted the policy of reflexing all first time anti-HDV positive samples into the HDV PCR assay. This study supports the recommendation that anti-HDV serology precedes PCR testing, as all PCR positive samples in this study had detectable antiHDV. The low proportion positive for HDAg reinforces its limitations as a diagnostic assay. While useful in diagnosing acute infection (28), HDV RNA is much more reliable and clinically relevant for the determination of current infection.

This study reports for the first time on the circulating genotypes found in Australia. Unsurprisingly the predominant genotype was 1 (80.5\%), which has a global distribution. Genotype 5, first described in Africa, represented 16\% of isolates (13). This correlates with the increased number of cases born in Africa described in the surveillance data. Six isolates (3.5\%) were genotype 2, reported in Japan and other Asian countries including Vietnam (29, 30). The genotype 2 strains documented in this study may well reflect the significant numbers of Australians born in Vietnam (31). Genotype 2 and 5 tended to be detected in younger patients, likely reflecting the younger age of patients immigrating into Australia from the Asia and Africa.

Determination of genotype alone, particularly genotype 1, offers a low level of discrimination as HDV genotypes can differ by up to $40 \%$ of their genome $(5,11)$. Phylogenetic analysis was performed in this study to further evaluate relatedness of the strains circulating in Australia. Five patients with the genotype 5 strain (figure 3) were born in either Liberia or Sierra Leone located on the west coast of Africa. These results are consistent with reports of genotype 5 in other West African countries including Mauritania (32), Cameroon (33) and Nigeria (34). In contrast the genotype 1 African strains from Australian patients tended to originate from East Africa (Figure 2). In this study there were 8 patients born in Sudan and 1 in Egypt, correlating with previously published data of genotype 1 isolates in Egypt and Somalia $(35,36)$. 
This study detected eight genotype 1 isolates that clustered with the previously reported PI strain (14), which had previously only been described in Kiribati and neighbouring Nauru. These Australian isolates were detected in patients residing in Queensland however the three with known country of birth were from the PI's of Kiribati, Fiji and Nauru. A previous report (37) has suggested that Kiribati may be the source of HDV infection for other PI's such as the Solomon Islands and Nauru, which are also hyperendemic $(38,39)$. Our study expands the range of the PI HDV strain to Australia.

Phylogenetic analysis revealed four clusters within genotypes 1, 2 and 5 (figures 2 and 3) where individuals were from the same residential address. These results reinforce the importance of testing close contacts of people living with HBV/HDV co-infection. Phylogenetic analysis also suggested potential transmission between individuals residing in correctional facilities, highlighting this group as a population at risk.

A limitation of this study is it only represents those individuals who have received testing and may not reflect all people living with HDV in Australia. Further research is required to thoroughly assess local testing patterns and epidemiology and to provide an estimate of the true prevalence of HDV. Linkage of Victorian laboratory testing with notifications data in other states would help expand available information on prevalence and risk factors of HDV in Australia as a whole.

There was a paucity of HDV PCR testing at this laboratory from residents of some Australian states, such as New South Wales. HDV PCR testing is not a Medicare-rebatable test, which discourages confirmatory testing by clinicians. The addition of an HDV PCR test to the Medicare Benefits Schedule would allow for more widely accessible clinical management of HDV in Australia and improve patient care.

Our findings demonstrate that HDV infection is not rare in this country, and that increasing testing identified infection in people who were previously undiagnosed. HBV/HDV coinfection can cause more severe liver disease than HBV mono-infection, resulting in accelerated progression of cirrhosis, hepatic decompensation and hepatocellularcarcinoma and an increased risk of fulminant hepatitis $(1,2)$. Interferon therapy is currently the only option for treatment of HDV infection. However there are many new and investigational therapeutics on the horizon targeting both HBV and/or HDV including entry inhibitors such as Myrcludex B in combination with tenofovir (40), prenylation inhibitors, RNA interfering molecules and nucleic acid polymers. 
The diversity in risk factors, geographic origin and the findings suggesting under-diagnosis highlight the need for routine HDV testing of all people diagnosed with HBV, as well as any individuals with unexplained worsening of clinical symptoms, as recommended in clinical guidelines (41) Hence we re-affirm that all new HBsAg positive individuals be tested for anti-HDV to assess exposure, as well as individuals with unexplained worsening of clinical symptoms. In those who test positive, follow-up HDV PCR testing is essential to assess the presence of current infection and assist with clinical management. Conclusion

Although this study describes HDV prevalence in Australia, the implications of the source of HDV from immigration, the importance of testing close contacts, and the lessons learnt with regards follow-up of positive serology, have a universal significance.

\section{Acknowledgements}

Thanks to Professor Graham Cooksley, Dr Mazhar Haque and Dr Lilly Yuen for technical assistance

\section{References}

1. Noureddin M \& Gish R (2014) Hepatitis delta: epidemiology, diagnosis and management 36 years after discovery. Current gastroenterology reports 16(1):365.

2. Rizzetto M (2015) Hepatitis D Virus: Introduction and Epidemiology. Cold Spring Harbor perspectives in medicine 5(7):a021576.

3. Koytak ES, Yurdaydin C, \& Glenn JS (2007) Hepatitis d. Current treatment options in gastroenterology 10(6):456-463.

4. Alfaiate D, Deny P, \& Durantel D (2015) Hepatitis delta virus: From biological and medical aspects to current and investigational therapeutic options. Antiviral research 122:112-129.

5. Alves C, Branco C, \& Cunha C (2013) Hepatitis delta virus: a peculiar virus. Advances in virology 2013:560105.

6. Hughes SA, Wedemeyer H, \& Harrison PM (2011) Hepatitis delta virus. Lancet 378(9785):7385.

7. Romeo R, et al. (2009) A 28-year study of the course of hepatitis Delta infection: a risk factor for cirrhosis and hepatocellular carcinoma. Gastroenterology 136(5):1629-1638.

8. Dimitrakakis M, Waters MJ, Wootton AL, \& Gust ID (1986) Epidemiology of hepatitis D virus (delta) infection in Melbourne over a 15-year period. The Medical journal of Australia 145(34):128-130.

9. Shadur B, MacLachlan J, \& Cowie B (2013) Hepatitis D virus in Victoria 2000-2009. Internal medicine journal 43(10):1081-1087.

10. Hughes SA, Wedemeyer H, \& Harrison PM (2011) Hepatitis delta virus. Lancet.

11. Rizzetto M (2009) Hepatitis D: thirty years after. Journal of hepatology 50(5):1043-1050.

12. Rizzetto M (2009) Hepatitis D: the comeback? Liver international : official journal of the International Association for the Study of the Liver 29 Suppl 1:140-142.

13. Radjef N, et al. (2004) Molecular phylogenetic analyses indicate a wide and ancient radiation of African hepatitis delta virus, suggesting a deltavirus genus of at least seven major clades. Journal of virology 78(5):2537-2544. 
14. Han M, et al. (2014) Molecular epidemiology of hepatitis delta virus in the Western Pacific region. Journal of clinical virology : the official publication of the Pan American Society for Clinical Virology 61(1):34-39.

15. Sakugawa $\mathrm{H}$, et al. (1999) Hepatitis delta virus genotype llb predominates in an endemic area, Okinawa, Japan. Journal of medical virology 58(4):366-372.

16. Chang SY, et al. (2011) Molecular epidemiology of hepatitis D virus infection among injecting drug users with and without human immunodeficiency virus infection in Taiwan. Journal of clinical microbiology 49(3):1083-1089.

17. Ivaniushina V, et al. (2001) Hepatitis delta virus genotypes I and II cocirculate in an endemic area of Yakutia, Russia. The Journal of general virology 82(Pt 11):2709-2718.

18. Nakano T, et al. (2001) Characterization of hepatitis B virus genotypes among Yucpa Indians in Venezuela. The Journal of general virology 82(Pt 2):359-365.

19. Nakano T, et al. (2001) Characterization of hepatitis D virus genotype III among Yucpa Indians in Venezuela. The Journal of general virology 82(Pt 9):2183-2189.

20. Deny P (2006) Hepatitis delta virus genetic variability: from genotypes I, II, III to eight major clades? Current topics in microbiology and immunology 307:151-171.

21. Matthews G, Robotin M, \& Allard NL eds (2014) B Positive: All You Wanted to Know About Hepatitis B - A Guide for Primary Care Providers (ASHM, Darlinghurst, NSW 1300).

22. World Health Organisation (2015) Guidelines for the prevention, care and treatment of persons with chronic hepatitis $B$ infection.

23. Ayres A, Locarnini S, \& Bartholomeusz A (2004) HBV genotyping and analysis for unique mutations. Methods in molecular medicine 95:125-149.

24. Benson DA, Karsch-Mizrachi I, Lipman DJ, Ostell J, \& Wheeler DL (2005) GenBank. Nucleic acids research 33(Database issue):D34-38.

25. Katoh K \& Standley DM (2013) MAFFT multiple sequence alignment software version 7: improvements in performance and usability. Molecular biology and evolution 30(4):772-780.

26. Hall TA (1999) BioEdit: a user-friendly biological sequence alignment editor and analysis program for Windows 95/98/NT. Nucl Acids Symp Ser 41:95-98.

27. Tamura K, et al. (2011) MEGA5: molecular evolutionary genetics analysis using maximum likelihood, evolutionary distance, and maximum parsimony methods. Molecular biology and evolution 28(10):2731-2739.

28. Le Gal F, et al. (2005) Quantification of hepatitis delta virus RNA in serum by consensus realtime PCR indicates different patterns of virological response to interferon therapy in chronically infected patients. Journal of clinical microbiology 43(5):2363-2369.

29. Nguyen HM, et al. (2017) Prevalence and genotype distribution of hepatitis delta virus among chronic hepatitis B carriers in Central Vietnam. PloS one 12(4):e0175304.

30. Sy BT, et al. (2015) Identification of a natural intergenotypic recombinant hepatitis delta virus genotype 1 and 2 in Vietnamese HBsAg-positive patients. Journal of viral hepatitis 22(1):55-63.

31. MacLachlan JH \& Cowie BC (2013) Hepatitis B Mapping Project: Estimates of CHB prevalence and cultural and linguistic diversity by Medicare Local - National Report 2011. (Australasian Society for HIV Medicine and Victorian Infectious Diseases Reference Laboratory, Darlinghurst), pp Available from http://www.ashm.org.au/hepatitis-B/mapping.

32. Mansour W, et al. (2012) Virological and epidemiological features of hepatitis delta infection among blood donors in Nouakchott, Mauritania. Journal of clinical virology : the official publication of the Pan American Society for Clinical Virology 55(1):12-16.

33. Foupouapouognigni Y, Noah DN, Sartre MT, \& Njouom R (2011) High prevalence and predominance of hepatitis delta virus genotype 1 infection in Cameroon. Journal of clinical microbiology 49(3):1162-1164.

34. Andernach IE, et al. (2014) Characterization of hepatitis delta virus in sub-Saharan Africa. Journal of clinical microbiology 52(5):1629-1636. 
35. Saudy N, et al. (2003) Genotypes and phylogenetic characterization of hepatitis B and delta viruses in Egypt. Journal of medical virology 70(4):529-536.

36. Zhang YY, Tsega E, \& Hansson BG (1996) Phylogenetic analysis of hepatitis D viruses indicating a new genotype I subgroup among African isolates. Journal of clinical microbiology 34(12):3023-3030.

37. Tibbs CJ (1989) Delta hepatitis in Kiribati: a pacific focus. Journal of medical virology 29(2):130-132.

38. Speed BR, Dimitrakakis M, Thoma K, \& Gust ID (1989) Control of HBV and HDV infection in an isolated Pacific Island: 1. Pattern of infection. Journal of medical virology 29(1):13-19.

39. Dimitrakakis M, Crowe S, \& Gust I (1986) Prevalence of delta infection in the western Pacific region. Journal of medical virology 18(4):335-339.

40. Wedemeyer $\mathrm{H}$, et al. (2008) Final results of a multicenter, open-label phase $2 \mathrm{~b}$ clinical trial to assess safety and efficacy of Myrcludex B in combination with Tenofovir in patients with chronic HBV/HDV co-infection. Journal of hepatology 68(Supplement 1):S3.

41. Anonymous (2017) EASL 2017 Clinical Practice Guidelines on the management of hepatitis B virus infection. Journal of hepatology 67(2):370-398.

Table 1. Demographic and clinical characteristics of HDV notifications and laboratory tests, 2000-2009 (historical data) (9) and 2010-2016 (current study)

\begin{tabular}{|c|c|c|}
\hline & $2000-2009(9)$ & 2010-2016 (this study) \\
\hline \multicolumn{3}{|l|}{ Notifications data } \\
\hline Total number & 87 & 90 \\
\hline \multicolumn{3}{|l|}{ Sex } \\
\hline Male & $67(77.0 \%)$ & $59(65.5 \%)$ \\
\hline Female & $20(23.0 \%)$ & $31(34.4 \%)$ \\
\hline Median age (IQR) in years & $34(27-44)$ & $40(31-50)$ \\
\hline \multicolumn{3}{|l|}{ Injecting drug use } \\
\hline History of injecting & $30(34.5 \%)$ & $22(24.4 \%)$ \\
\hline No injecting drug use & $3(1.2 \%)$ & $44(54.3 \%)$ \\
\hline Unknown/Not stated & $54(62.1 \%)$ & $24(26.7 \%)$ \\
\hline \multicolumn{3}{|l|}{ Country of birth } \\
\hline Australia & $16(18.4 \%)$ & $18(18.9 \%)$ \\
\hline Sudan & $9(10.3 \%)$ & $19(21.1 \%)$ \\
\hline Vietnam & $9(10.3 \%)$ & $6(6.7 \%)$ \\
\hline Liberia & $4(4.6 \%)$ & $1(1.1 \%)$ \\
\hline Romania & $3(3.5 \%)$ & $2(2.2 \%)$ \\
\hline Lebanon & $2(2.3 \%)$ & - \\
\hline Pakistan & - & $6(6.7 \%)$ \\
\hline Afghanistan & - & $3(3.3 \%)$ \\
\hline Sierra Leone & - & $3(3.3 \%)$ \\
\hline Countries with 2 cases each: & & $\begin{array}{l}\text { Burma, Philippines, } \\
\text { Somalia, Turkey }(2.2 \% \\
\text { each) }\end{array}$ \\
\hline
\end{tabular}

This article is protected by copyright. All rights reserved. 


\begin{tabular}{|c|l|l|}
\hline Countries with 1 case each: & $\begin{array}{l}\text { Afghanistan, Croatia, Kenya, } \\
\text { Kiribati, Laos, Nauru, New } \\
\text { Zealand, Sierra Leone, } \\
\text { Uganda, Ukraine, 'Sub- } \\
\text { Saharan Africa', 'South East } \\
\text { Asia' and 'Overseas not } \\
\text { specified (1.1\% each) }\end{array}$ & $\begin{array}{l}\text { China, Republic of the } \\
\text { Congo, Ethiopia, Laos, } \\
\text { Liberia, Nigeria, Thailand, } \\
\text { Uganda, Uzbekistan, } \\
\text { 'Overseas not specified' } \\
(1.1 \% \text { each) }\end{array}$ \\
\hline Not stated or unknown & $31(35.6 \%)$ & $15(16.7 \%)$ \\
\hline Correctional facility status & $10(11.5 \%)$ & $5(5.6 \%)$ \\
\hline In a correctional facility & $18(20.7 \%)$ & $85(94.4 \%)$ \\
\hline Not in correctional facility & $59(67.8 \%)$ & $26(25.2 \%)$ \\
\hline Not reported & $21(24.1 \%)$ & $48(53.3 \%)$ \\
\hline Reason for testing* & $8(9.2 \%)$ & $8(8.9 \%)$ \\
\hline Symptoms** & $51(58.6 \%)$ & 5,078 individuals \\
\hline Screening & & 264 individuals (3.8\%) \\
\hline Not reported & 2314 individuals & $5(5=$ anti-HDV positive) \\
\hline Laboratory data & 110 individuals (4.8\%) & $1,351(890$ individuals $)$ \\
\hline $\begin{array}{l}\text { HDV serology (anti-HDV and/or } \\
\text { HDAg) testing requests }\end{array}$ & $6(3=$ antiHDV positive) & \\
\hline HDV serology positive & $227(161$ individuals $)$ & \\
\hline HDAg positive & & \\
\hline HDV PCR testing requests & & \\
\hline
\end{tabular}

$*$ Other reasons $<2 \%$ not presented.

**Includes abnormal liver function tests, acute hepatitis, cirrhosis, liver decompensation.

Table 2. Sample requests for HDV serology and PCR by year and proportion positive and equivocal results.

\begin{tabular}{|l|l|l|l|l|l|}
\hline Year & $\begin{array}{l}\text { Serology } \\
\text { Requests }\end{array}$ & $\begin{array}{l}\text { Anti-HDV } \\
\text { positive }\end{array}$ & $\begin{array}{l}\text { Anti-HDV } \\
\text { Equivocals }\end{array}$ & $\begin{array}{l}\text { No. PCR } \\
\text { Requests }\end{array}$ & $\begin{array}{l}\text { No. PCR } \\
\text { Positives }\end{array}$ \\
\hline 2010 & 410 & $21(5.1)^{*}$ & 3 & 110 & $25(23)$ \\
\hline 2011 & 531 & $32(6.0)$ & 5 & 160 & $41(26)$ \\
\hline 2012 & 530 & $25(4.7)$ & 4 & 129 & $44(34)$ \\
\hline 2013 & 693 & $45(6.5)$ & 3 & 180 & $60(33)$ \\
\hline 2014 & 989 & $49(5.0)$ & 7 & 252 & $85(34)$ \\
\hline 2015 & 1188 & $39(3.3)$ & 12 & 233 & $61(26)$ \\
\hline 2016 & 1206 & $53(4.4)$ & 5 & 287 & $78(27)$ \\
\hline Total & $\mathbf{5 5 4 7}$ & $\mathbf{2 6 4}(\mathbf{4 . 8})$ & $\mathbf{3 9}$ & $\mathbf{1 3 5 1}$ & $\mathbf{3 9 4}(\mathbf{2 9})$ \\
\hline
\end{tabular}

*Figures in parentheses represent percentage

This article is protected by copyright. All rights reserved. 
Table 3. Proportion of anti-HDV positive patients with associated request for PCR and PCR result.

\begin{tabular}{|ccccc|ccc|}
\hline Year & $\begin{array}{c}\text { Anti- } \\
\text { HDV } \\
\text { Positives }\end{array}$ & $\begin{array}{c}\text { PCR } \\
\text { Requests }\end{array}$ & $\begin{array}{c}\text { PCR } \\
\text { Positive }\end{array}$ & $\begin{array}{c}\text { PCR } \\
\text { Negative }\end{array}$ & $\begin{array}{c}\text { PCR Not } \\
\text { requested } \\
\text { but } \\
\text { tested }\end{array}$ & $\begin{array}{c}\text { PCR } \\
\text { Positive }\end{array}$ & $\begin{array}{c}\text { PCR } \\
\text { Negative }\end{array}$ \\
\hline 2010 & 14 & 9 & 4 & 5 & & & \\
2011 & 26 & 12 & 8 & 4 & & & \\
2012 & 16 & 7 & 5 & 2 & & 2 & 8 \\
2013 & 38 & 17 & 7 & 10 & 10 & 2 & 2 \\
2014 & 36 & 18 & 5 & 13 & 10 & 8 & $\mathbf{1 0}$ \\
TOTAL & $\mathbf{1 3 0}$ & $\mathbf{6 3}(\mathbf{4 8 \%})$ & $\mathbf{2 9}$ & $\mathbf{3 4}$ & $\mathbf{2 0}$ & $\mathbf{1 0}$ & $\mathbf{( 4 6 \% )}$ \\
\hline
\end{tabular}

Figure 1a. The age of the patients at the time of HDV RNA detection

Figure1b. Shows the genotypes prevailing in the year HDV RNA was first detected.

Figure 2. A maximum likelihood phylogenetic tree showing the inferred relationship between the genotype 1 sequences isolated from this study and HDV sequences of known genotype retrieved from Genbank (403nt) Accession numbers and country of origin of the sequences downloaded from Genbank are indicated on the tree. Support values for the branches $>60 \%$ are indicated. The HDV sequences from this study are marked in red with known country of origin indicated. 
Figure 3. A maximum likelihood phylogenetic tree showing the inferred relationship between the genotype 2 and 5 sequences isolated from this study and HDV sequences of known genotype retrieved from Genbank (401nt) Accession numbers and country of origin of the sequences downloaded from Genbank are indicated on the tree. Support values for the branches $>60 \%$ are indicated. The HDV sequences from this study are marked with a red square, with known country of origin indicated. 


\section{University Library}

\section{- M M N E R VA A gateway to Melbourne's research publications}

Minerva Access is the Institutional Repository of The University of Melbourne

\section{Author/s:}

Jackson, K;MacLachlan, J;Cowie, B;Locarnini, S;Bowden, S;Higgins, N;Karapanagiotidis, T;Nicholson, S;Littlejohn, M

Title:

Epidemiology and phylogenetic analysis of hepatitis D virus infection in Australia

\section{Date:}

2018-11-01

\section{Citation:}

Jackson, K., MacLachlan, J., Cowie, B., Locarnini, S., Bowden, S., Higgins, N., Karapanagiotidis, T., Nicholson, S. \& Littlejohn, M. (2018). Epidemiology and phylogenetic analysis of hepatitis D virus infection in Australia. INTERNAL MEDICINE JOURNAL, 48 (11), pp.1308-1317. https://doi.org/10.1111/imj. 13967.

Persistent Link:

http://hdl.handle.net/11343/284755 